third of patients. Tachycardia, agitation, and lethargy are the most frequent symptoms. Accidental ingestion is more common than intentional exposure, and therapeutic error occurs most frequently during the 6 to 11 year-old period. The potential for the development of lethargy and impaired consciousness argues against the use of syrup of ipecac or charcoal in prehospital recommended treatment measures.

\title{
HERITABILITY OF ADHD
}

A twin study design was used to examine the the genetic validity of attention deficit hypoeractivity disorder (ADHD)-related phenotypes. Parent-rated symptoms were reported by questionnaires received for 2082 twin pairs, and teacher-rated symptoms were available for 1470 twin pairs. Parent-rated, teacherrated, and both parent and teacher-rated ADHD categories were highly heritable. Shared environmental effects were found for teacher-rated ADHD. ADHD reported by both parent and teacher is as heritable as ADHD symptoms defined only by maternal reports. A common genetic factor influences maternal and teacherrated ADHD but not all teacher-rated ADHD. Teacher reports alone may be distinct from parent-rated ADHD, since they are influenced by shared environmental factors and by additional genetic and nonshared environmental factors. (Thapar A, Harrington R, Ross K, McGuffin P. Does the definition of ADHD affect heritability? LAm Acad Child Adolesc Psychiatry Dec 2000;39:1528-1536). (Respond: Dr Thapar, Child and Adolescent Psychiatry Section, Department of Psychological Medicine, University of Wales College of Medicine, Heath Park, Cardiff, Wales, UK CF14 4XN).

COMMENT. Broadly defined pervasive (both parent and teacher-rated) ADHD symptoms are as heritable as ADHD behaviors defined by maternal reports alone. A common genetic factor influences maternally rated and teacher rated ADHD. ADHD symptoms are highly heritable.

Dopamine D4 receptor gene and ADHD. Linkage of the dopamine D4 receptor gene and $\mathrm{ADHD}$ is supported by further studies at Toronto Western Hospital (Sunohara GA, Roberts W, Malone M et al. L Am Acad Child Adolesc Psychiatry Dec 2000;39:1537-1542).

Is ADHD a noradrenergic disorder? This topic is reviewed by Biederman J and Spencer TJ (I Am Acad Child Adolesc Psychiatry Oct 2000;39:1330). Data implicate norepinephrine dysfunction and frontosubcortical pathways that control attention and motor behavior. Drugs with anti-ADHD activity share a common noradrenergic/dopaminergic activity.

\section{ROLE OF TEMPORAL LOBE IN AUTISM}

Regional cerebral blood flow was measured with positron emission tomography (PET) in 21 school-aged children with primary autism and in 10 nonautistic children with idiopathic mental retardation, at the Institut National de la Sante, Tours, and Hopital La Salpetriere, Paris, France. A highly significant hypoperfusion was noted in both temporal lobes, centered in auditory and adjacent cortex, in $76 \%$ of autistic children. (Zilbovicius M, Boddaert N, Belin P et al. Temporal lobe dysfunction in childhood autism: a PET study. Am I Psychiatry Dec 2000;157:1988-1993). (Reprints: Dr Zilbovicius, Commisariat a l'Energie Atomique, Service Hopitalier Frederic Joliot, 4 place du General Leclerc, 91406, Orsay, France).

COMMENT. Hypoperfusion in the temporal lobes of children with primary autism suggests a temporal lobe dysfunction as the basis for the variety of 
perceptive, cognitive, and affective deficits found with this disorder.

Macrocephaly and autism. The prevalence of macrocephaly ( $>97$ th centile) in autism and other pervasive developmental disorders was studied in 41 autistic children and in 21 children with tuberous sclerosis. Macrocephaly was diagnosed in $12 \%$ of probands with autism and in $15 \%$ of their first-degree relatives. These were higher prevalence rates than in normal children and in the comparison group of probands with TS $(9.5 \%)$ and their first-degree relatives $(8.3 \%)$. Macrocephaly may be a familal risk factor in the pathogenesis of autism. (Fidler DJ, Bailey JN, Smalley SL. Dev Med Child Neurol Nov 2000;42:737-740).

Prognosis of autism and Asperger's syndrome. Children with Asperger's syndrome had better social skills and fewer autistic symptoms when studied at 2 year follow-up than children with autism. (Szatnari P, Bryson SE, Streiner DL et al. Am J Psychiatry Dec 2000;157:1980-1987).

\section{VASCULAR MALFORMATIONS}

\section{SURGICAL OUTCOME IN STURGE-WEBER SYNDROME}

The presurgical epilepsy profile, criteria for surgery, and postoperative outcome of epilepsy were assessed in 20 patients with Sturge-Weber syndrome (SWS) consecutively admitted to the Hopital des Enfants Malades in Paris and the Montreal Neurological Institute. One had a callosotomy, 5 a hemispherectomy, and 14 had cortical excision. Age at onset of seizures ranged from 2 months to 12 years, and age at operation was at 8 months to 34 years. Visually guided complete resection of the pial angioma and underlying cortex was of benefit in most patients. Thirteen of 20 in the total group and all 5 patients with hemispherectomy became seizure-free. None showed worsening of cognitive impairment. (Arzimanaglou AA, Andermann F, Aicardi J et al. Sturge-Weber syndrome. Indications and results of surgery in 20 patients. Neurology Nov (2 of 2);55:1472-1479). (Reprints: Dr Alexis Arzimanoglou, Epilepsy Program, Service de Neurologie Pediatrique et des Maladies Metaboliques, Hopital Robert Debre, 48 Boulevard Serurier, 75019, Paris, France).

COMMENT. In patients with Sturge-Weber syndrome and drug-resistant epilepsy early surgery should be considered. Lesionectomy may be sufficient to control seizures when the pial angioma is unilateral, Hemispherectomy may be justified if the lesion is diffuse and causing a motor deficit and if symptoms are rapidly progressive.

Sturge-Weber syndrome with early onset seizures. The criteria for early epilepsy surgery were studied at the Child Developmental Center and Pediatric Neurology Unit, Tel Aviv Sourasky Medical Center, by a retrospective review of all Israeli infants with SWS and early onset seizures (before 18 months of age). Seizures presented at age 2 to 10 months. Five of 15 patients underwent surgery. Two undergoing surgery at 8 to 17 months have normal IQ at follow-up, whereas three operated at age 22 to 27 months have MR or borderline IQ At mean follow-up period of 15 years for all patients, 6 had normal IQ 4 had borderline IQ 3 mild mental retardation, and two had moderate mental retardation. Eight of 10 patients not operated still have seizures. Cognitive impairment was significantly correlated with seizure intensity in the early period, but not with age of seizure onset or seizure recurrences. (Kramer U, Kahana E, Shorer Z, Ben-Zeev B. Dev Med Child Neurol Nov 2000;42:756-759). 